\title{
Editorial
}

\section{Polimeros termoconmutables}

En años recientes, una de las áreas de los polímeros más ampliamente investigadas, por las importantes aplicaciones tecnológicas a que pueden dar lugar, es la síntesis de macromoléculas conmutables o sensibles a cambios en el medio ambiente tales como; por ejemplo, temperatura, $\mathrm{pH}$, luz, y campo eléctrico o magnético. Este tipo de polímeros, conmutables o sensibles, tienen alto potencial para aplicaciones en biomateriales, en microsistemas, sensores y catálisis, entre otros. Entre los polímeros conmutables que más se han investigado se encuentran los polímeros termosensibles.

Se pueden obtener polímeros con respuesta térmica usando los homopolímeros y copolímeros de N-isopropilacrilamida, N-vinilcaprolactama, y vinilmetiléter. Sin embargo, en años recientes, se descubrió que también algunos polímeros de 2-oxazolinas tienen la propiedad de tener sensibilidad térmica, tales como, poli(isopropil-2-oxazolina), poli(n-propil-2oxazolina), poli(etil-2-oxazolina) y poli(ciclopropil-2-oxazolina).

Los polímeros termosensibles presentan, en solución acuosa, una transición conformacional bien definida, donde las propiedades físicas cambian drásticamente en un estrecho rango de temperatura. Esta temperatura es denominada en inglés "Low critical solution temperature" (LCST). Por ejemplo, los polímeros de N-isopropilacrilamida, cuando están disueltos en agua, pasan a los 32 grados centígrados de un estado hidrofílico a un estado hidrofóbico y precipitan o se dispersan en el medio acuoso y este fenómeno es reversible, ya que, al disminuir la temperatura por debajo de $\operatorname{los} 32^{\circ} \mathrm{C}$, se disuelven nuevamente, pudiendo servir, entonces, como un "switch" o un interruptor macromolecular. Esta temperatura LCST se puede disminuir o aumentar al copolimerizar la $\mathrm{N}$-isopropilacrilamida con monómeros hidrofóbicos o hidrofílicos, respectivamente, o mediante la adición de surfactantes o sales inorgánicas. Se pueden obtener temperaturas de transición cercanas a la temperatura corporal humana, abriendo la posibilidad para aplicaciones tecnológicas muy interesantes.

La transición conformacional LCST se puede utilizar en términos prácticos, por ejemplo, para elaborar hidrogeles termosensibles que puedan servir como sistemas de liberación controlada de medicamentos y fertilizantes, en ingeniería de tejidos o en válvulas y sensores para microfluidos.

En el Perú, se debe promover la investigación básica y aplicada en polímeros y, en particular, en este tipo de polímeros conmutables que tienen un potencial de alto valor agregado. Se deben formar, en nuestro país, recursos humanos especializados en los polímeros tradicionales, pero también en los polímeros funcionalizados o con propiedades especiales. 